\title{
Patterns of drug taking in patients with chronic airflow obstruction
}

\author{
P.N.E. James ${ }^{1}$, J.B. Anderson ${ }^{*}$, J.G. Prior ${ }^{2}$, J.P. White ${ }^{1 \dagger}$, J.A. Henry ${ }^{2}$ and G.M. \\ Cochrane $^{2 \dagger}$
}

${ }^{\prime}$ Department of Medicine, Guy's Hospital Medical School, London S.E.1; ${ }^{2}$ Department of Thoracic Medicine, New Cross Hospital, London SE14 SER, UK.

\begin{abstract}
Summary: A questionnaire on the pattern of drug taking was completed by 185 patients with chronic airflow obstruction. Of these, $49 \%$ admitted to taking their prescribed therapy regularly and $33 \%$ could be regarded as being fully compliant. The use of increasing numbers of drugs was not accompanied by a fall in compliance. Regular drug taking was better in patients (particularly females) with asthma than in patients with chronic bronchitis and emphysema. During acute exacerbations of airflow obstruction, excessive use of bronchodilators beyond the recommended increase in medication was rare; indeed, underuse of therapy in this situation was commoner. These conclusions must be regarded as tentative since the questionnaire was not validated by repeat interviewing or measurement of drug usage.
\end{abstract}

\section{Introduction}

In chronic airflow obstruction different classes of drugs are often used in combination, and in regimens requiring multiple daily doses of each agent. The resulting dosage schedules are often extremely complex. It has been considered that complex treatment regimens should result in poor compliance (Blackwell, 1973; Matthews \& Hingson, 1977; Gatley, 1968), although the evidence for this is not conclusive (Haynes et al, 1977; Haynes, 1979).

We have compared the pattern of drug taking with recommended therapy in patients with chronic airflow obstruction using a simple questionnaire.

\section{Methods}

The questionnaire consisted of three questions:

(1) What was the prescribed therapy?

(2) What therapy did the patient take when well?

(3) What adjustments (if any) were made to this therapy during exacerbations of symptoms?

P.N.E. James, M.B., M.R.C.P.; J.B. Anderson, M.B., M.R.C.P.; J.G. Prior, M.D., M.R.C.P.; J.P. White, M.B., M.R.C.P.; J.A. Henry, M.B., M.R.C.P.; G.M. Cochrane, M.B., M.R.C.P

Correspondence: G.M. Cochrane

Present addresses: *Brook Hospital, London S.E.18; †Welsh National School of Medicine, Llandough Hospital, Llandough, South Glamorgan.

Accepted: 30 May 1984
The questionnaire was completed by 185 patients attending one chest clinic and two allergy/asthma clinics in the North Southwark and Lewisham Health District. One hundred and forty two patients were diagnosed as being asthmatic and 43 had chronic bronchitis and emphysema. The latter group were all smokers and reversibility of airflow obstruction following bronchodilators was less than in the group with asthma. In each case the questionnaire was actually completed by the attending physician. The patients were informed that the survey was a research procedure, and that their answers would be taken down on a form separate from their notes, and that their answers would not be used to coerce them in any way. The answers given by the patients could not be verified and so had to be taken at face value. Occasional lapses of memory were not taken as representing poor compliance.

Patients received extensive verbal advice regarding their disease and therapy. At the time of the survey this was not reinforced by written advice. The patients were asked to take their therapy regularly (save those using inhaled bronchodilators on a symptomatic basis) and advised that they could increase their inhaled beta-sympathomimetic agents to as much as 20 puffs per day, if necessary, during exacerbations of their symptoms. They were also warned that this is an important sign that their asthma is deteriorating (Cochrane, 1979), and that they should contact their general practitioner or the physician at the clinic for further advice under these circumstances (Crompton et al., 1979). A few patients with severe, steroid

(C) The Fellowship of Postgraduate Medicine, 1985 
responsive asthma were provided with oral corticosteroids to take during exacerbations.

From the results of the questionnaire we derived two indices of compliance; compliance with maintenance therapy (i.e. those patients who took their prescribed therapy regularly), and full compliance (those patients who not only took their prescribed therapy regularly, but also adjusted their therapy as advised during exacerbations of their symptoms by increasing the dose of inhaled bronchodilators, but not the doses of prophylactic agents). Statistical comparisons were made using Fisher's exact test.

\section{Results}

The results of the 185 completed questionnaires are shown in Table I. Full compliance was significantly higher in patients with asthma than in those with chronic bronchitis and emphysema $(P<0.05)$. Full compliance was also higher in female patients than in males $(P<0.05)$, and in female asthmatic patients compared to male asthmatics $(P<0.05)$.

The majority of the non-compliant patients took less than their regular prescribed therapy but only 8 (4\%) discontinued therapy completely. Only 3 patients regularly took more than their prescribed therapy when well.

The different classes of drugs prescribed and patient compliance with each is illustrated in Figure 1. The vast majority (183) of patients were prescribed inhaled beta-sympathomimetic agents, often in combination with inhaled corticosteroids. One hundred and thirteen $(62 \%)$ of the patients taking inhaled beta-sympathomimetic agents took their prescribed dose regularly. Compliance for inhaled corticosteroids $(62 \%)$, and inhaled anticholinergic agents $(80 \%)$ were similar. Comparatively few patients were prescribed oral theophyllines and daily oral corticosteroids, but $88 \%$ claimed regular use of theophyllines and $95 \%$ oral corticosteroids. All but two of these patients were also taking inhaled beta-sympathomimetic agents. Compliance for inhaled beta-sympathomimetic agents was higher $(77 \%)$ in this sub-group of patients, than in the patients as a whole.

The relationship between the number of prescribed drugs and compliance is shown in Table II. Compliance with maintenance therapy and full compliance in those taking three or more drugs was not statistically different from those taking two drugs or fewer $(P<0.1)$.

\section{Therapy taken during exacerbations of symptoms}

One hundred and sixty eight patients were using inhaled beta-sympathomimetic agents via conven- $\overrightarrow{-}$ tional aerosol inhalers or rotary inhalers. During acute $\vec{\perp}$ exacerbations of symptoms 108 increased dose of beta- $v$ sympathomimetic agent whilst the rest continued with 을 maintenance therapy. If the dose of inhaled bron- $\vec{c}$ chodilator is compared on the basis of the equivalent number of puffs from a conventional inhaler on a simple weight basis, then the majority of patients (81) increased the dose up to the equivalent of 25 puffs per day. A further 22 patients increased the dose to the equivalent of 25-50 puffs per day, and 3 patients to $51-100$ puffs per day. One patient took more than $10 \bar{\theta}$. puffs per day. These increases represent changes of up to $700 \%$ over the prescribed dosage.

Six $(25 \%)$ patients taking oral theophyllines increased their dose during exacerbations of their symptoms. In 4 this merely entailed taking one extra slowrelease (SR) tablet per day. One patient who did not take his prescribed $225 \mathrm{mg}$ SR aminophylline b.d.

Table I The relationship between compliance, diagnosis and sex. Full compliance was significantly higher in female asthmatic patients than in male asthmatic patients, and in all female patients compared to all male patients $(P<0.05)$. Full compliance is significantly higher in all patients with asthma than in those with chronic bronchitis and emphysema $(P<0.05)$.

\begin{tabular}{|c|c|c|c|}
\hline & Male & Female & Total \\
\hline \multicolumn{4}{|l|}{ Asthma } \\
\hline Number & 65 & 77 & 142 \\
\hline Compliance with maintenance therapy & $29(45 \%)$ & $42(55 \%)$ & $71(50 \%)$ \\
\hline Full compliance & $16(25 \%)$ & $34(44 \%)$ & $50(35 \%)$ \\
\hline \multicolumn{4}{|l|}{ Chronic bronchitis and emphysema } \\
\hline Number & 38 & 5 & 43 \\
\hline Compliance with maintenance therapy & $17(45 \%)$ & $3(60 \%)$ & $20(47 \%)$ \\
\hline Full compliance & $6(16 \%)$ & $2(40 \%)$ & $8(19 \%)$ \\
\hline \multicolumn{4}{|l|}{ All patients } \\
\hline Number & 103 & 82 & 185 \\
\hline Compliance with maintenance therapy & $46(45 \%)$ & $45(54 \%)$ & $91(49 \%)$ \\
\hline Full compliance & $22(21 \%)$ & $36(43 \%)$ & $58(31 \%)$ \\
\hline
\end{tabular}


Table II Number of drugs taken by each patient related to compliance with therapy.

\begin{tabular}{lcrr}
\hline $\begin{array}{l}\text { Number } \\
\text { of drugs }\end{array}$ & $\begin{array}{c}\text { Number of } \\
\text { patients }\end{array}$ & $\begin{array}{c}\text { Compliance with } \\
\text { maintenance therapy }\end{array}$ & $\begin{array}{c}\text { Full } \\
\text { compliance }\end{array}$ \\
1 & 24 & $9(38 \%)$ & $6(25 \%)$ \\
2 & 94 & $44(47 \%)$ & $26(28 \%)$ \\
3 & 47 & $26(55 \%)$ & $15(32 \%)$ \\
4 & 19 & $11(58 \%)$ & $10(53 \%)$ \\
5 & 1 & & 1
\end{tabular}

when well, took $225 \mathrm{mg}$ t.d.s. and one $350 \mathrm{mg}$ aminophylline suppository b.d. during exacerbations of his symptoms. One 17 year old female at her first attendance at the clinic increased her prescribed therapy of theophylline $100 \mathrm{mg}$ t.d.s. to $400 \mathrm{mg}$ t.d.s. during exacerbations of her symptoms.

Some patients increased their usage of other drugs during exacerbations of symptoms. Twelve $(10 \%)$ patients taking inhaled corticosteroids, and $5(12.5 \%)$ taking inhaled anticholinergic agents increased the dose during exacerbations of their symptoms. Nine $(39 \%)$ of the patients taking oral corticosteroids increased the dose during exacerbations of symptoms, and a further 10 patients, who were not rigularly prescribed oral corticosteroids, took a short reducing course of oral steroids as provided for use during exacerbations.

\section{Discussion}

This study attempts to compare prescribed therapy with actual daily drug taking (compliance) in patients with chronic airflow obstruction. Unfortunately, techniques for precise monitoring of inhaled therapy (using measurements of plasma drug concentrations) are not yet available, and assessment of compliance was made using a questionnaire. Because of the scale of the survey, techniques such as pill counting and weighing of inhalers was not considered feasible. A criticism of the study is that patients' answers had to be taken at face value and could not be verified. However. we have no reason to believe that the patients would deliberately mislead us.

It is logical to keep therapeutic regimens as straightforward as possible, avoiding multiple medications and reducing the number of daily doses to a minimum (Blackwell, 1973; Matthews \& Hingson, 1977; Editorial, 1977; Blackwell, 1979), although such advice has been questioned (Haynes et al., 1977). In patients with rheumatoid arthritis, compliance was better with an anti-inflammatory analgesic than with placebo, suggesting that effective relief of symptoms is important in ensuring regular administration of therapy (Rooney, 1978). In our patients compliance did not decline with increasing complexity of drug regimens. The use of multiple drug therapy was usually necessitated by poor control of symptoms; it is likely that relief of symptoms was an important factor

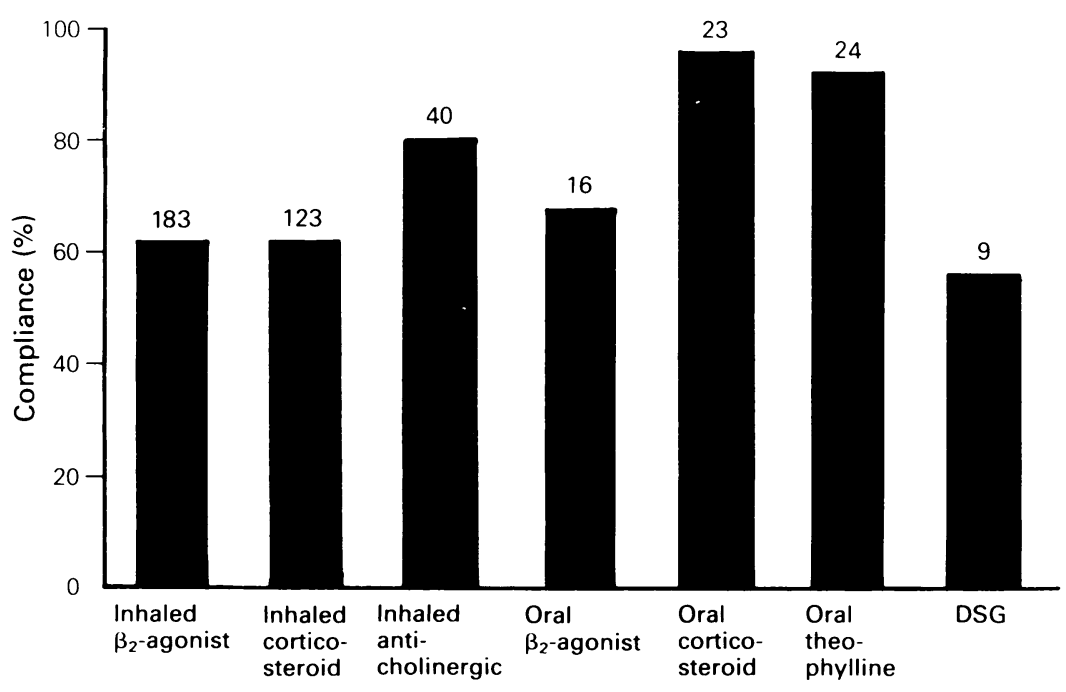

Figure 1 Compliance in relation to drugs. The numbers over the histogram represent the number of patients taking each class of drug. DSG: disodium cromoglycate. 
ensuring regular treatment taking, over-riding the deleterious effect of a complicated therapeutic regimen on compliance. This might explain why full compliance was better in asthmatic patients than those with chronic bronchitis and emphysema, since bronchodilator therapy is likely to be more effective in those whose airways obstruction shows greater reversibility. The finding of better compliance in female patients than their male counterparts is surprising and difficult to explain. It warrants further investigation.

The suggestion has been made that excessive use of bronchodilators in patients with worsening airflow obstruction is an important factor contributing to deaths from asthma (Wilson, et al., 1981; Speitzer er al., 1968). Our study, however, suggests that under-use of bronchodilators during severe asthma is common, since most patients did not take more than the equivalent of $2.5 \mathrm{mg}$ salbutamol daily $(20 \mathrm{mg}$ nebulized salbutamol daily being the recommended bronchodilator therapy in acute severe asthma) (Editorial, 1981). Although direct comparisons between the amount of drug reaching the lung delivered by pressurized inhaler and the nebulizer are difficult to quantify, it seem unlikely that dosage used by the majority of the patients was 'excessive'. Furthermore, we feel that only two patients took potentially toxic doses of methylxanthines.

Non-adherence to therapy appears common in patients with chronic airflow obstruction. However,

\section{References}

BLACKWELL, B. (1973). Patient compliance. New England Journal of Medicine, 289, 249.

BLACKWELL, B. (1979). The drug regimen and treatment compliance. Compliance in Health Care. Haynes, R.B., Taylor, D.W. \& Sackett, D.L. (eds.) Johns Hopkins University Press: Baltimore, p. 144.

COCHRANE, G.M. (1979). Bronchodilators. The Practitioner, 223, 489.

CROMPTON, G.K., GRANT, I.W.B. \& BLOOMFIELD, P. (1979). Edinburgh Emergency Asthma Service: report on 10 years' experience. British Medical Journal, ii, 1199.

EDITORIAL (1977). Keep on taking the tablets. British Medical Journal, i, 793.

EDITORIAL (1981). Acute severe asthma. Lancet, i, 313.

GATLEY, M.S. (1968). To be taken as directed. Journal of the Royal College of General Practitioners, 16, 39.

HAYNES, R.B., SACKETT, D.L., TAYLOR, D.W., ROBERTS, R.S. \& JOHNSON, A.L. (1977). Manipulation of the therapeutic regimen to improve compliance: Conceptions and misconceptions. Clinical Pharmacology and Therapeutics, 23, 125. most patients tended to reduce the dosage of their therapy rather than stop it completely. In a disease where patients are encouraged to increase their therapy when unwell, it is perhaps not surprising that many reduce their therapy when well. This might also suggest that some patients had been prescribed more therapy than they actually required. In many cases, control of symptoms remained good on the reduced dosage. However, the survey also identified a minority of patients in whom poor compliance contributed to poor control of symptoms, often complicated by lack of understanding of their therapy. Perhaps these patients could be helped by more intensive counselling and written instructions on their therapy and appropriate adjustments, possibly with the addition of an objective measurement such as peak flow (Prior \& Cochrane, 1980).

Compliance with therapy in patients with chronic airflow obstruction would appear not to be reduced by the use of more complex therapeutic regimens, and excessive use of bronchodilator therapy appears uncommon in such patients. Under-use of therapy is, perhaps, a more worrying problem.

\section{Acknowledgements}

We would like to acknowledge the continued support and encouragement of Professor Tim Clark, and to thank Mis J.M. Wright for typing the manuscript.
HAYNES, R.B. (1979). Determinants of compliance. The disease and the mechanics of treatment. In: Compliance in Health Care, Haynes, R.B., Taylor, D.W. \& Sackett, D.L. (eds.) Johns Hopkins University Press: Baltimore, p. 49.

MATTHEWS, D. \& HINGSON, R. (1977). Improving patient compliance. Medical Clinics of North America, 61, 879.

ROONEY, P.J. (1978). Continued use of non-steroidal antiinflammatory drugs: an index of clinical efficacy. British Journal of Clinical Pharmacology, 5, 453.

PRIOR, J.G. \& COCHRANE, G.M. (1980). Home monitoring of peak expiratory flow rate using the mini-Wright peak flow meter in the diagnosis of asthma. Journal of the Royal Society of Medicine, 73, 731.

SPEITZER, F.E., DOLL, R., HEAF, P. \& STRANG, L.B. (1968). Investigation into use of drugs preceding death from asthma. British Medical Journal, i, 339.

WILSON, J.D., SUTHERLAND, D.C. \& THOMAS, A.C. (1981). Has the change to beta-agonists combined with oral theophylline increased cases of fatal asthma? Lancet, $\mathbf{i}$, 1235. 